\title{
Multiscale Modeling of Thiol Overoxidation in Peroxiredoxins by ${ }_{2}$ Hydrogen Peroxide
}

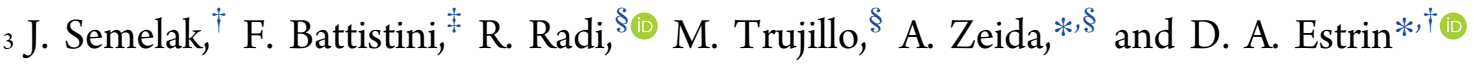 \\ $4{ }^{\dagger}$ Departamento de Química Inorgánica, Analítica y Química Física, INQUIMAE-CONICET, Facultad de Ciencias Exactas y \\ 5 Naturales, Ciudad Universitaria, Pab. 2, CP 1428, Buenos Aires, Argentina \\ $6{ }^{\ddagger}$ Institute for Research in Biomedicine (IRB Barcelona), The Barcelona Institute of Science and Technology, 08028 Barcelona, Spain \\ $7{ }^{\S}$ Departamento de Bioquímica and Centro de Investigaciones Biomédicas (CEINBIO), Facultad de Medicina, Av. Gral. Flores 2125, \\ 8 CP 11800 Montevideo, Uruguay
}

\section{S Supporting Information}

10 ABSTRACT: In this work, we employ a multiscale quantum11 classical mechanics (QM/MM) scheme to investigate the 12 chemical reactivity of sulfenic acids ( $\mathrm{RSOH})$ toward hydrogen 13 peroxide, both in aqueous solution and in the protein 14 environment of the peroxiredoxin alkyl hydroperoxide 15 reductase E from Mycobacterium tuberculosis (MtAhpE). The 16 reaction of oxidation of cysteine with hydrogen peroxides, 17 catalyzed by peroxiredoxins, is usually accelerated several 18 orders of magnitude in comparison with the analogous 19 reaction in solution. The resulting cysteine sulfenic acid is

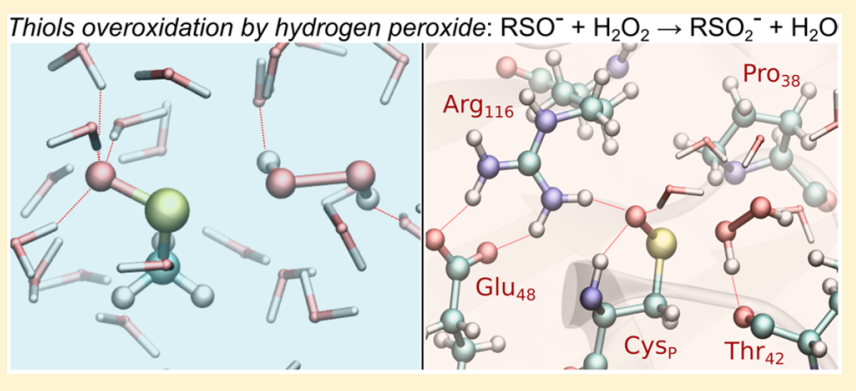
then reduced in other steps of the catalytic cycle, recovering the original thiol. However, under some conditions, the sulfenic acid can react with another equivalent of oxidant to form a sulfinic acid $\left(\mathrm{RSO}_{2} \mathrm{H}\right)$. This process is called overoxidation and has been associated with redox signaling. Herein, we employed a multiscale scheme based on density function theory calculations coupled to the classical AMBER force field, developed in our group, to establish the molecular basis of thiol overoxidation by hydrogen peroxide. Our results suggest that residues that play key catalytic roles in the oxidation of $M t A h p E$ are not relevant in the overoxidation process. Indeed, the calculations propose that the process is unfavored by this particular enzyme microenvironment.

\section{INTRODUCTION}

27 Computer simulation techniques provide an excellent tool to 28 shed light on the molecular basis of chemical and biological 29 processes. Specifically, reactive processes in complex environ30 ments can be dealt with using multiscale techniques which may 31 be envisaged in two different schemes. One method consists of 32 applying different levels of theory in a sequential way, i.e., using 33 classical atomistic molecular dynamics (MD) simulations 34 followed by quantum mechanics (QM) calculations of a 35 selected part of the system. The other method consists of 36 applying simultaneously the two techniques, considering one 37 part of the system described at one level of theory while the 38 rest is treated at the other level, i.e., the standard hybrid 39 quantum classical techniques (QM/MM).

40 In our group we have developed two different QM/MM 41 codes; one is based on a numerical DFT scheme coupled to 42 the AMBER force field. ${ }^{1}$ Using this method, we have 43 investigated several reactions by computing potential energy 44 profiles and elucidated reaction mechanisms for processes both 45 in solution, such as the chorismate to prephenate conversion, ${ }^{1}$ 46 or in protein environments, such as the NO detoxification 47 mechanism catalyzed by truncated hemoglobin $\mathrm{N}$ of 48 Mycobacterium tuberculosis ${ }^{2}$ and the catalytic mechanism and 49 the detection of a novel intermediate in indoleamine 2,3- deoxygenase. $^{3}$ The other code, named LIO, is based on a 50 Gaussian basis set approach, has been optimized for running in 51 GPU, ${ }^{4,5}$ and has been extensively used for the investigation of 52 reaction mechanisms and selectivity of hydroperoxides with 53 the cysteine catalyzed reaction in peroxiredoxin, as well as in 54 aqueous solution, yielding in both cases the corresponding 55 sulfenic acid (reaction 1). The use of an appropriate 56 combination of classical MD followed by a computationally 57 efficient QM/MM code allowed us to achieve a more extensive 58 sampling of the configurational space and to obtain free energy 59 profiles. The free energy profiles provide information on 60 kinetic and thermodynamics properties that could be 61 compared directly with experimental values, since both thermal 62 and entropic effects are included, which are not considered in 63 potential energy profiles.

Herein, we illustrate the combination of classical MD and 65 QM/MM MD with two reactivity problems in complex 66 environments. In the first place, we analyze the reaction of a 67

Special Issue: Molecular Simulation in Latin America: Coming of Age

Received: September 19, 2019

Published: November 13, 2019 
68 model sulfenic acid with hydrogen peroxide in aqueous 69 solution that yields the corresponding sulfinic acid $\left(\mathrm{RSO}_{2} \mathrm{H}\right)$. 70 [According to their low $\mathrm{p} K_{\mathrm{a}}$ values $(\sim 2$ for free cysteine), these 71 compounds exist mostly under the deprotonated, sulfinate 72 form at physiological $\mathrm{pH}^{6}{ }^{6}$ ] This is an extremely challenging 73 problem due to the dynamical nature of aqueous solvation. In 74 the second place, we analyze the same reaction in another 75 challenging situation, a protein that presents a highly 76 nanoheterogeneous environment.

77 Cysteine sulfinic acids $\left(\mathrm{Cys}-\mathrm{SO}_{2} \mathrm{H}\right)$ are oxidized forms of 78 either free or protein Cys residues. Free Cys oxidation to 79 sulfinic acid, catalyzed by $\mathrm{Fe}^{2+}$-dependent $\mathrm{Cys}$ dioxygenases, is 80 the first step in the catabolic route of the amino acid. ${ }^{6}$ In turn, 81 protein $\mathrm{Cys}-\mathrm{SO}_{2} \mathrm{H}$, initially considered an oxidative post82 translational modification arising mostly as an artifact from 83 purification processes, is now known to occur in vivo, in 84 different proteins. ${ }^{7,8}$ Indeed, quantitative analysis estimated 85 that $\mathrm{Cys}-\mathrm{SO}_{2} \mathrm{H}$ accounts for $\sim 1-2 \%$ of total Cys residues in 86 the soluble proteins of the rat liver. ${ }^{9}$ The formation of sulfinic 87 acid can involve two consecutive two-electron oxidations of 88 thiolates $\left(\mathrm{RS}^{-}\right)$: the first yielding a sulfenate $\left(\mathrm{RSO}^{-}\right.$; reaction $891)$, which is then further oxidized to sulfinate $\left(\mathrm{RSO}_{2}{ }^{-}\right.$; reaction $902)$, in a process that is often referred to as over- or 91 hyperoxidation. ${ }^{10,11}$

$$
\begin{array}{ll}
92 & \mathrm{RS}^{-}+\mathrm{R}^{\prime} \mathrm{OOH} \rightarrow \mathrm{RSO}^{-}+\mathrm{R}^{\prime} \mathrm{OH} \\
93 & \mathrm{RSO}^{-}+\mathrm{R}^{\prime} \mathrm{OOH} \rightarrow \mathrm{RSO}_{2}^{-}+\mathrm{R}^{\prime} \mathrm{OH}
\end{array}
$$

(reaction 2)

94 Alternatively, sulfinic acid could result from the one-electron 95 oxidation of thiolates to thiyl radicals $\left(\mathrm{RS}^{\bullet}\right)$ followed by a 96 reaction with oxygen, reorganization of the corresponding thio97 peroxyl radical ( $\mathrm{RSOO}^{\bullet}$ ) to a sulfonyl radical $\left(\mathrm{RS}(\mathrm{O}) \mathrm{O}^{\bullet}\right)$, 98 which can eventually be reduced to sulfinic acid. ${ }^{12-14}$ Among 99 all the biologically relevant two-electron oxidants involved in 100 overoxidation reactions, hydrogen peroxide $\left(\mathrm{H}_{2} \mathrm{O}_{2}\right)$ has a 101 recognized role in redox signaling processes. ${ }^{15,16}$ The kinetics 102 of the reaction of $\mathrm{H}_{2} \mathrm{O}_{2}$ with free cysteine and other aliphatic 103 low molecular weight (LMW) thiols is $\mathrm{pH}$-dependent, since $104 \mathrm{pH}$ affects thiolate availability depending on thiol acidity. ${ }^{17}$ In 105 addition, $\mathrm{pH}$-independent rate constants are higher-usually 106 in the $10^{1} \mathrm{M}^{-1} \mathrm{~s}^{-1}$ range at $25{ }^{\circ} \mathrm{C}$ - for those thiolates of 107 higher basicity, according to their higher nucleophilicity. ${ }^{18}$

108 In the case of cysteine residues, the protein microenviron109 ment can largely affect reactivity. Among the proteins 110 susceptible to cysteine modification to sulfinic acid (see 111 Table 1 for examples and determined rate constants),

Table 1. Bimolecular Rate Constants of Protein Cys

\begin{tabular}{|c|c|c|c|}
\hline protein & $k^{\prime}\left(\mathrm{M}^{-1} \mathrm{~s}^{-1}\right)$ & conditions & references \\
\hline \multirow[t]{2}{*}{ human Prx1 } & 1770 & $\mathrm{pH} 7.4 ; 25{ }^{\circ} \mathrm{C}$ & 44 \\
\hline & 57 & $\mathrm{pH} 7.0 ; 30{ }^{\circ} \mathrm{C}$ & 45 \\
\hline \multirow[t]{2}{*}{ human Prx2 } & 1970 & 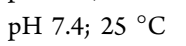 & 44 \\
\hline & 6000 & $\mathrm{pH} 7.4 ; 25^{\circ} \mathrm{C}$ & 46 \\
\hline \multirow[t]{2}{*}{ human Prx3 } & 1100 & $\mathrm{pH} 7.8 ; 14^{\circ} \mathrm{C}$ & 47 \\
\hline & 6000 & $\mathrm{pH} 7.4 ; 25^{\circ} \mathrm{C}$ & 46 \\
\hline M. tuberculosis AhpE & 40 & $\mathrm{pH} 7.4 ; 25{ }^{\circ} \mathrm{C}$ & 26 \\
\hline human serum albumin & 0.4 & $\mathrm{pH} \mathrm{7.4;3} 7^{\circ} \mathrm{C}$ & 48 \\
\hline Cdc25B phosphatase & 60 & $\mathrm{pH} 7.0 ; 20{ }^{\circ} \mathrm{C}$ & 49 \\
\hline Cdc25C phosphatase & 110 & $\mathrm{pH} 7.0 ; 20{ }^{\circ} \mathrm{C}$ & 49 \\
\hline \multirow[t]{2}{*}{ S. faecalis NADH peroxidase } & 0.14 & $\mathrm{pH} 7.0 ; 25^{\circ} \mathrm{C}$ & 50 \\
\hline & 0.11 & $\mathrm{pH} 7.0 ; 25^{\circ} \mathrm{C}$ & 51 \\
\hline
\end{tabular}
Overoxidation by Hydrogen Peroxide peroxiredoxins (Prxs) deserve particular attention. These 112 enzymes catalyze the two-electron reduction of hydroperoxides 113 such as hydrogen peroxide, organic hydroperoxides, and 114 peroxynitrite by ping-pong bisubstratic kinetic mecha- 115 nisms. ${ }^{19-21}$ In the oxidizing part of the catalytic cycle, the 116 peroxidatic cysteine of Prxs $\left(\mathrm{Cys}_{\mathrm{P}}\right)$ performs the nucleophilic 117 attack on the hydroperoxide yielding the corresponding 118 alcohol as the first product, while the peroxidatic thiol 119 $\left(\mathrm{Cys} \mathrm{s}_{\mathrm{p}} \mathrm{SH}\right)$ is oxidized to sulfenic acid $\left(\mathrm{Cys}_{\mathrm{p}}-\mathrm{SOH}\right)$. The 120 oxidation of peroxidatic thiols in Prxs by hydroperoxides is 121 usually very rapid $\left(10^{4}\right.$ to $\left.10^{8} \mathrm{M}^{-1} \mathrm{~s}^{-1}\right) .^{12,22}$ Unfortunately, due 122 to the instability of aliphatic LMW sulfenic acids, experimental 123 determinations of the rate constants of their overoxidation are 124 almost lacking. ${ }^{23-25} \mathrm{pH}$ profile of $\mathrm{H}_{2} \mathrm{O}_{2}$-mediated protein Cys- 125 $\mathrm{SOH}$ oxidation indicated sulfenate as the reactive species, ${ }^{26}$ in 126 agreement with computational results. ${ }^{27}$ In 2-Cys Prxs there is 127 a resolution step in which $\mathrm{CysP}-\mathrm{SOH}$ reacts with the resolving 128 Cys $\left(\mathrm{Cys}_{\mathrm{R}}\right)$ to form a disulfide bond. The latter is then reduced 129 by thioredoxin or a related enzyme. In 1-Cys Prxs, $\mathrm{Cys}_{\mathrm{P}}-\mathrm{SOH} 130$ is reduced to $\mathrm{Cys}_{\mathrm{p}}-\mathrm{SH}$ by different mechanisms, depending on 131 the particular enzyme. ${ }^{19}$ Prxs are prone to inactivation by 132 oxidizing substrates, through the reaction of a second 133 hydroperoxide moiety with $\mathrm{Cys}_{\mathrm{P}}-\mathrm{SOH}$ yielding $\mathrm{Cys}_{\mathrm{P}}-\mathrm{SO}_{2} \mathrm{H}^{28}{ }_{134}$ Prxs overoxidation second-order rate constants are usually 135 $\sim 10^{3}$ times lower than the oxidation ones considering the same 136 hydroperoxide. $^{29-31}$ The susceptibility of different Prxs to 137 oxidative inactivation depends on how rapidly overoxidation 138 occurs with respect to other possible pathways of $\mathrm{Cys}_{\mathrm{P}}-\mathrm{SOH} .139$ In particular, overoxidation competes with resolution in 2-Cys 140 Prxs, $^{32}$ or with mixed disulfide formation with other cellular 141 thiols both in two-cysteine and 1-Cys Prxs. ${ }^{32}$ Sulfinylation can 142 promote protein ubiquitination and degradation by the 143 proteasome. ${ }^{33}$ Furthermore, $\mathrm{Cys}_{\mathrm{P}}-\mathrm{SO}_{2} \mathrm{H}$ in some Prxs can be 144 reduced back to $\mathrm{Cys}_{\mathrm{P}}-\mathrm{SOH}$ by sulfiredoxins, ATP-dependent 145 enzymes which have been recently reported to also catalyze the 146 reduction of other sulfinylated proteins. ${ }^{7,34}$ The reversible 147 inactivation of Prxs due to sulfinylation and reactivation 148 through sulfiredoxin is the basis of the floodgate hypothesis of 149 redox signaling. ${ }^{32}$

In many Prxs, redox changes are associated with changes in 151 their quaternary structures, which importantly affect the 152 enzyme function ${ }^{35-37}$ and can also affect the susceptibility to 153 overoxidation. $^{38,39}$ In turn, overoxidation of some Prxs 154 promotes the formation of higher molecular weight complexes 155 which acquire chaperone activity. ${ }^{40}$

In this work, we employed a combination of classical MD 157 and QM/MM schemes to describe the molecular basis of $\mathrm{Cys}_{\mathrm{P}} 158$ overoxidation in atomistic detail, choosing as a member of the 159 peroxiredoxin (Prx) family the 1-Cys alkyl hydroperoxide 160 reductase $\mathrm{E}$ from Mycobacterium tuberculosis (MtAhpE, see 161 Figure 1). This enzyme is dimeric and reduces different $162 \mathrm{fl}$ hydroperoxides using either mycothiol/mycoredoxin-1 or 163 hydrogen sulfide as a reducing substrate..$^{26,29,41-43}$ When the 164 protein is oxidized, it is also dimeric at least during short 165 incubation times (minutes). MtAhpE $\mathrm{Cys}_{\mathrm{P}}-\mathrm{SOH}$ is relatively 166 stable, its $\mathrm{p} K_{\mathrm{a}}$ is 6.6 at $25{ }^{\circ} \mathrm{C}$ and its rate constant of $\mathrm{H}_{2} \mathrm{O}_{2}-167$ mediated overoxidation is $42 \mathrm{M}^{-1} \mathrm{~s}^{-1}$ at $25{ }^{\circ} \mathrm{C}$. ${ }^{26}$ We present a 168 detailed description of the multiscale simulations approach to 169 investigate this chemical process both in aqueous solution and 170 in the protein environment and correlate our results with 171 experimental findings. 

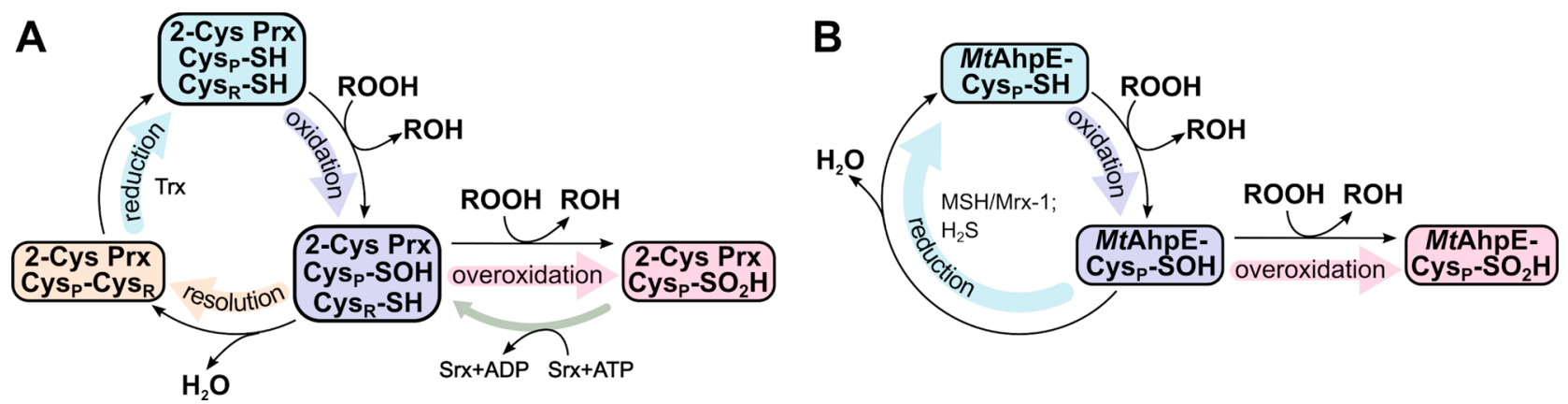

Figure 1. Catalytic cycle of 2-Cys Prxs and MtAhpE. After oxidation of $\mathrm{Cys}_{\mathrm{P}}$ to sulfenic acid (violet), the possibility of overoxidation to sulfinic acid by a second hydroperoxide molecule is represented (pink). In 2-Cys Prxs (A), overoxidation competes with enzyme resolution (orange) followed by reduction (cyan) mostly relying on thioredoxin (Trx). In some eukaryotic 2-Cys Prxs, sulfiredoxins (Srx) may reduce the sulfinic acid back to sulfenic acid at the expense of ATP. For MtAhpE (B), two reduction pathways need to be recognized, mycothiol/mycoredoxin-1 (MSH/Mrx-1) or hydrogen sulfide (see the text).

\section{METHODS}

173 The oxidation of the model system methanesulfenate $174\left(\mathrm{MeSO}^{-}\right)$by $\mathrm{H}_{2} \mathrm{O}_{2}$ was studied employing electronic structure 175 calculations in vacuo. We then performed $\mathrm{QM} / \mathrm{MM}$ 176 simulations to study the reaction of $\mathrm{MeSO}^{-}$in aqueous 177 solution and MtAhpE-Cys $\mathrm{p}_{\mathrm{p}}-\mathrm{SO}^{-}$with $\mathrm{H}_{2} \mathrm{O}_{2}$. In each case, $178 \mathrm{QM} / \mathrm{MM}$ simulations were performed by describing the 179 solvent water molecules at the MM level of theory, and key 180 atoms of reactants were selected to constitute the QM 181 subsystem. $\mathrm{MeSO}^{-}$and $\mathrm{H}_{2} \mathrm{O}_{2}$ were treated entirely as quantum 182 residues while only the methylene and $-\mathrm{SO}^{-}$of the $\mathrm{Cys}_{\mathrm{p}}$ 183 (Cys45) were considered in the case of MtAhpE. A detailed 184 description of the protocols employed is given in the next 185 subsections.

186 2.1. Molecular Dynamics Simulations. Classical molec187 ular dynamics (MD) simulations of the MtAhpE dimer were 188 performed for the thiolate form of the reduced enzyme $189\left(\mathrm{MtAhpE}-\mathrm{S}^{-}\right)$and for the sulfenate form $\left(\mathrm{MtAhpE-S0^{- }}\right)$. The 190 X-ray crystal structures of the enzyme in both states were 191 retrieved from the Protein Database (PDB). Two original 192 structures (PDB ID: 1XXU and $1 \mathrm{XVW})^{52}$ and their reviewed 193 version by using a new refinement algorithm specially 194 developed for sulfur $\mathrm{H}$-bonds in proteins (PDB ID: 4XOX 195 and 4X1U) were considered. ${ }^{53}$ We performed relatively long $196 \mathrm{MD}$ simulations starting from the four structures described 197 above, but nonsignificant differences were observed between 198 the original and the revised structures (see Supporting 199 Information Figure S1). We decided to continue the 200 simulations and analyses using the more recently reported 201 structures. $^{53}$

202 The four initial models were studied using the same MD 203 protocol. Each system was solvated with an octahedral box of $20412 \AA$ in radius with TIP3P water molecules. ${ }^{54}$ Protein 205 parameters correspond to the parm14SB Amber force field ${ }^{55}$ 206 with the exception of the parameters for the Cys-SO ${ }^{-}$residue 207 that were developed using standard protocols. ${ }^{56}$ Simulations 208 were performed using periodic boundary conditions with a 10 $209 \AA$ cutoff and particle mesh Ewald summation method for 210 treating the electrostatic interactions. The hydrogen bond 211 lengths were kept at their equilibrium distance by using the 212 SHAKE algorithm, ${ }^{57}$ while temperature and pressure were kept 213 constant with a Langevin thermostat ${ }^{58}$ and barostat, ${ }^{59}$ 214 respectively, as implemented in the AMBER14 program. 215 Each system was minimized in 1000 steps (10 with steepest 216 descent and the rest with conjugate gradient). It was then heated from 0 to $300 \mathrm{~K}$ for $20 \mathrm{ps}$ at constant pressure, with a 217 Berendsen thermostat, ${ }^{60}$ and pressure was equilibrated at 1 bar 218 for 5 ps. After these two steps, a $10 \mathrm{~ns}$ MD long simulation at 219 constant temperature $(300 \mathrm{~K})$ and constant volume was 220 performed followed by an unrestrained 700-ns-long production 221 MD at the NPT ensemble.

In order to study the overoxidation process, after character- 223 ization of the equilibrium properties of the different systems, a 224 $\mathrm{H}_{2} \mathrm{O}_{2}$ molecule was placed at the active site of the $\mathrm{Cys}_{\mathrm{p}}-\mathrm{SO}^{-} 225$ system (4X1U) by replacing a water molecule close to $\mathrm{Cys}_{\mathrm{p}} 226$ present in the X-ray crystal structure. A 1- $\mu$ s-long MD 227 simulation was performed keeping the distance between a 228 peroxide oxygen atom and the sulfur atom less than $4.5 \AA$. To 229 achieve this, a restraint was applied, such that the external 230 potential on the mentioned distance was null between zero and 231 $4.5 \AA$ and rose sharply to higher values from $4.5 \AA$ onward 232 (acting as a "wall-like" potential). The parameters used for the 233 $\mathrm{H}_{2} \mathrm{O}_{2}$ molecule were obtained from previous works. ${ }^{42,61}$

2.2. Initial Survey of the Reaction in Model Systems. 235 All the electronic structure calculations were performed with 236 Gaussian $09 .^{62}$ Geometry optimizations at different stages of 237 the reaction were performed at the generalized gradient 238 approximation (GGA) level, using the PBE combination of 239 exchange and correlation functional, with a double- $\zeta$ plus 240 polarization (dzvp) Gaussian basis set. ${ }^{63}$ In each case, 241 frequency calculations were performed, and entropic con- 242 tributions were calculated as implemented in the Gaussian 09243 suite, which considers a harmonic potential and rigid rotor 244 approximation for vibrations and rotations. The transition state 245 structures were confirmed by performing intrinsic reaction 246 coordinate calculations. ${ }^{64}$ Additionally, reactions were studied 247 employing the Møller-Plesset perturbation theory (at the 248 MP2 level) with the dzvp basis to evaluate activation barrier 249 underestimations inherent to pure DFT functionals. ${ }^{65} 250$

2.3. QM/MM MD: System Initial Equilibration. QM/ 251 MM simulations were performed using LIO software, compiled 252 with Amber14, which is particularly efficient due to the use of 253 GPUs for the most consuming part of the calculations. ${ }^{4,66}$ In 254 each case, initial structures for the reactants were obtained 255 from ab initio, PBE-level geometry optimizations. The 256 reactants were placed in a truncated $25 \AA$ octahedral box 257 filled with TIP3P model water molecules. ${ }^{54}$ Periodic boundary 258 conditions were used, and each box contained only the 259 reactants and approximately 4000 explicit water molecules. 260 The Lennard-Jones parameters $(\varepsilon$ and $\sigma)$ for the quantum 261 
262 subsystem atoms were $0.2500,0.1094,0.2104$, and 0.0157 $263 \mathrm{kcal} / \mathrm{mol}$ and $2.000,1.9080,1.7210$, and $1.4870 \AA$, for S, C, O, 264 and $\mathrm{H}$, respectively. The system was optimized freezing the 265 classical water molecules and, second, restraining the QM 266 subsystem Cartesian coordinates with a quadratic bias 267 potential using a force constant of $400 \mathrm{kcal} / \mathrm{mol} \AA^{2}$, as 268 implemented in the Amber14 suit. Then, 0.1-ns-long classical 269 thermalization dynamics was performed, heating from 0 to 300 $270 \mathrm{~K}$, keeping the internal motion restraint on the reactant 271 complex (RC). Finally, a reliable thermalization of the solute 272 was ensured by a 1 ps QM/MM MD with an uncoupled 273 Berendsen thermostat, ${ }^{60}$ in order to control the local kinetic 274 energy of the relatively small QM subsystem. All dynamics 275 visualizations and molecular drawings were performed with 276 VMD 1.9.1. ${ }^{67}$

277 2.4. QM/MM MD Simulations: Free Energy Profiles 278 Calculation. 2.4.1. General Aspects and Reaction Coor279 dinate Choice. Free energy profiles were obtained using the 280 umbrella sampling method, a biased molecular dynamics based 281 method for the calculation of one- or more-dimensional free 282 energy profiles. ${ }^{68,69}$ Among the different proposed umbrella 283 sampling strategies, ${ }^{69}$ we employed the sampling method in 284 which intermediate steps between two thermodynamic states 285 are covered by a series of windows, at each of which a biased $286 \mathrm{MD}$ simulation is performed. The choice of an adequate 287 reaction coordinate and its representation using an order 288 parameter is an open issue in theoretical chemistry. ${ }^{70-72}$ 289 Importantly, this parameter is expected to be the degree of 290 freedom associated with the energetic barrier in the transition 291 process, and it is assumed to ensure that the "effective" 292 potential energy surface does not exhibit barriers, between the 293 initial and the final state, higher than thermal energy. If bonds 294 are being formed or broken through the process, distances 295 concerning the involved atoms should be included in the 296 selected degree of freedom, since it is well-known that the 297 breaking and the formation of bonds are processes which 298 usually exhibit great energetic changes. Once the free energy 299 profile is obtained, it is possible to verify whether the system 300 structure does not exhibit large conformational "jumps" going 301 from one window to another. ${ }^{73}$ If so, the selected order 302 parameter is likely adequate and the obtained results are 303 reliable. In our case, the order parameter $(\xi)$ that describes the 304 progress of the processes was defined as a combination of 305 geometric parameters. As stated before, this order parameter is 306 referred to as a reaction coordinate even though it might not 307 be the exact reaction coordinate of the system (i.e., the one308 dimensional coordinate that connects reactants and products 309 by the minimum free-energy pathway). In this work, the 310 reaction coordinate is defined in each case under study, given 311 by the difference between the nucleophilic sulfur atom and the 312 electrophilic center $\left(\mathrm{O}_{\mathrm{R}}\right.$ oxygen atom for $\left.\mathrm{H}_{2} \mathrm{O}_{2}\right)$ distance and 313 the distance between the electrophilic center and the closest 314 atom of the leaving group $\left(\mathrm{O}_{\mathrm{W}}\right.$ oxygen atom for $\left.\mathrm{H}_{2} \mathrm{O}_{2}\right)$. Atom 315 labels and reaction coordinates definitions are illustrated 316 below.

317 2.4.2. Windows Thermalization in a Charge-Reparamet318 rization Scheme. Initial structures for subsequent umbrella 319 sampling windows were obtained from a steered QM/MM $320 \mathrm{MD}$ simulation. In each case, the system was conducted from 321 the reactant to products in 25 ps using a force constant of 200 $322 \mathrm{kcal} / \mathrm{mol} \AA^{2}$. As we have shown in a previous work, solvent 323 pattern rearrangements related to charge redistribution during 324 the reaction are not well-sampled on the picosecond scale, and this might lead to overestimation of the free energy barriers 325 obtained. ${ }^{4}$ The windows were then carefully equilibrated in 326 order to improve solvation sampling, employing a 10-step cycle 327 which involved a $\mathrm{QM} / \mathrm{MM}$ recalculation of the classical 328 residue's charges and a $0.1 \mathrm{~ns} \mathrm{MM} \mathrm{MD}$ with an internal 329 motion restraint (force constant of $600 \mathrm{kcal} / \mathrm{mol} \AA^{2}$ ) in each 330 step. After each MM MD, a QM/MM optimization was 331 performed, and the topology was modified replacing the new 332 calculated charges of the QM subsystem for the next step. This 333 process was iteratively repeated 10 times, summing up to $1 \mathrm{~ns} 334$ of classical MD.

335

2.4.3. Free Energy Profiles Calculation. Equilibrated 336 structures obtained with the previously described charge 337 reparametrization scheme were used as initial coordinates for 338 each umbrella sampling window. The windows were centered 339 at different reaction coordinate reference values, spaced by 0.1340 $\AA$ in most of the cases, and it was verified that their 341 distributions overlapped. A quadratic bias potential function 342 (also centered in those reference values) was added to the 343 reaction coordinate in each window, and a 5-ps-long 344 uncoupled thermostat $\mathrm{QM} / \mathrm{MM} \mathrm{MD}$ was generated, followed 345 by a 10 ps long $\mathrm{QM} / \mathrm{MM}$ production $\mathrm{MD}$ using the stochastic 346 Langevin thermostat model in order to get a reliable canonical 347 distribution. Biased probability distributions along the reaction 348 coordinate $\left(P^{\mathrm{b}}\left(\xi_{i}\right)\right)$ were computed using only Langevin MD 349 data. Unbiased free-energy $G$ of the $i$ th window was then 350 recovered from biased simulations as

$$
G\left(\xi_{i}\right)=-R T \ln \left(P^{\mathrm{b}}\left(\xi_{i}\right)\right)-\frac{k}{2}\left(\xi_{i}-\xi_{i}^{\text {ref }}\right)^{2}+F_{i}
$$

where $T$ is the temperature $(300 \mathrm{~K}), R$ is the ideal gas 353 constant, $\xi_{i}^{\text {ref }}$ is the reference value of the window, $k$ is the bias 354 force constant $\left(100-200 \mathrm{kcal} / \mathrm{mol} \AA^{2}\right.$, depending on the 355 window), and $F_{i}$ is an integration constant that cannot be 356 directly obtained from the MD simulation. As mentioned 357 before, $P^{\mathrm{b}}\left(\xi_{i}\right)$ was directly obtained from the MD simulation. 358 Strictly, since the simulations were performed in the canonical 359 ensemble, eq 1 leads to the Helmholtz free energy. However, 360 for condensed systems, it could be considered practically 361 identical to Gibbs free energy. The complete free energy 362 profiles and statistical errors were finally obtained with the 363 umbrella integration method. ${ }^{69,74}$ An illustration of the 364 described methodology is shown in Figure 2.

\section{RESULTS AND DISCUSSION}

3.1. Structural and Dynamical Behavior of the 366 Enzyme in Different Redox States. The dynamical 367 properties of the MtAhpE dimer in the reduced state and its 368 interaction with different substrates have been investigated in 369 previous works by means of MD simulations ${ }^{42,43,61}$ and also by 370 NMR experiments. ${ }^{75}$ Nonetheless, the oxidized state $\left(\mathrm{Cys}_{\mathrm{P}^{-}} 371\right.$ $\mathrm{SO}^{-}$) has not been studied by dynamical techniques. As 372 predicted by the X-ray structures, the oxidation of $\mathrm{Cys}_{\mathrm{P}} 373$ resulted neither in large scale conformational changes in the 374 enzyme nor in significant changes in its dynamical behavior 375 (Figure $3 \mathrm{~A}$ and $\mathrm{B}$ ). In spite of that, an important local active $376 \mathrm{f3}$ site remodelling is noticed when going from $\mathrm{Cys}_{\mathrm{P}}-\mathrm{S}^{-}$to $\mathrm{Cys}_{\mathrm{P}^{-}} 377$ $\mathrm{SO}^{-}$states: the interaction network responsible for the 378 oxidation step acceleration, present when the enzyme is 379 reduced, ${ }^{4,61}$ gets perturbed by the oxidation of $\mathrm{Cys}_{\mathrm{p}} .380$ Specifically, the hydrogen bond interaction between $\mathrm{Cys}_{\mathrm{P}} 381$ and Thr42 is not present in the sulfenate state, and Arg116 382 also softens its association with $\mathrm{Cys}_{\mathrm{P}}$ as it interacts much more 383 


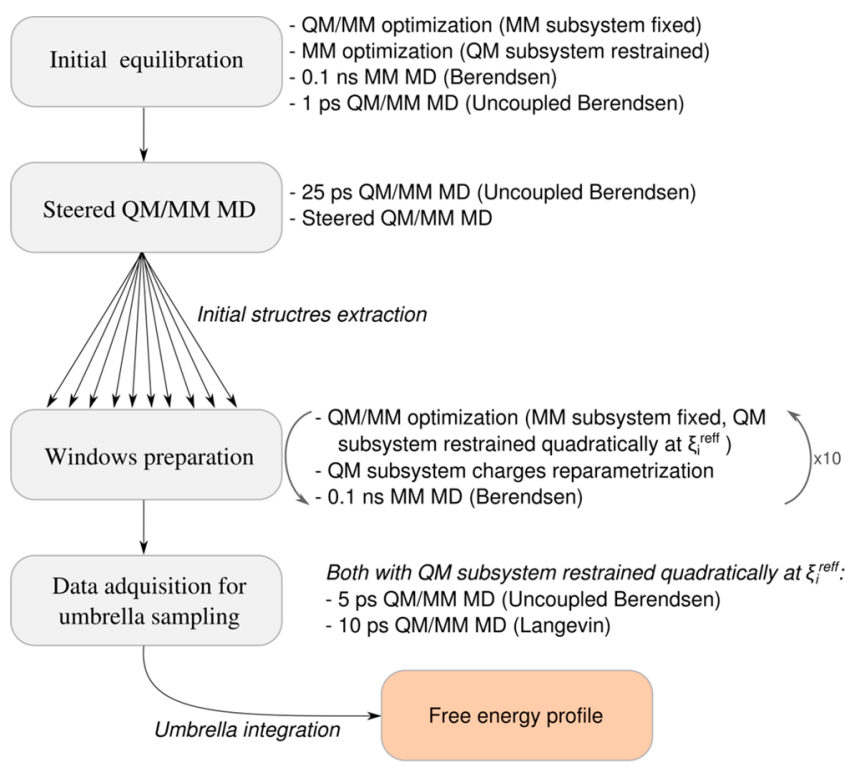

Figure 2. Pipeline representation of the simulation protocol used in this work for obtaining free energy profiles. strongly with Glu48 (Figure 3C-E). The fact the sulfenate of 384 $\mathrm{Cys}_{\mathrm{P}}$ is not particularly stabilized by Thr42 is consistent with 385 the sulfenic acid being less acidic than the thiol in this 386 enzyme. ${ }^{76}$ It is worth mentioning that no significant deviations 387 of the $\mathrm{C}-\mathrm{S}-\mathrm{O}_{\mathrm{S}}$ angle $\left(\sim 105-110^{\circ}\right)$ were observed either 388 within the three conformations sampled by classical MD 389 simulations or during QM/MM simulation sampling or the 390 evolution of the reaction (Supporting Information Figure S2), 391 in contrast with the $\sim 153^{\circ}$ observed in the case of 392 Xanthomonas campestris peroxiredoxin Q sulfenic acid 393 crystals. $^{77}$

These changes affect the positioning of the substrate 395 preceding the overoxidation reaction. When a $\mathrm{H}_{2} \mathrm{O}_{2}$ molecule 396 is placed at the MtAhpE-Cys $\mathrm{p}^{-} \mathrm{SO}^{-}$active site, at least three 397 different local conformations could be distinguished (Figure $398 \mathrm{f4}$ 4A). Two of these conformations (I and II) differ in the $399 \mathrm{f} 4$ hydroperoxide position with respect to $\mathrm{Cys}_{\mathrm{p}}$, with $\operatorname{Arg} 116400$ interacting directly with both $\mathrm{Cys}_{\mathrm{P}}$ and $\mathrm{H}_{2} \mathrm{O}_{2}$ in conformation 401 II (the most populated conformation within the $1 \mu \mathrm{s}$ MD 402 simulation) and only with $\mathrm{Cys}_{\mathrm{P}}$ in conformation I. The third 403 conformation corresponds to the insertion of $\mathrm{H}_{2} \mathrm{O}_{2}$ toward the 404 protein core, forcing an to Arg116 shift the active site outward 405 (Figure 4A and Supporting Information Figure S3). As the 406 three conformations showed different properties regarding the 407
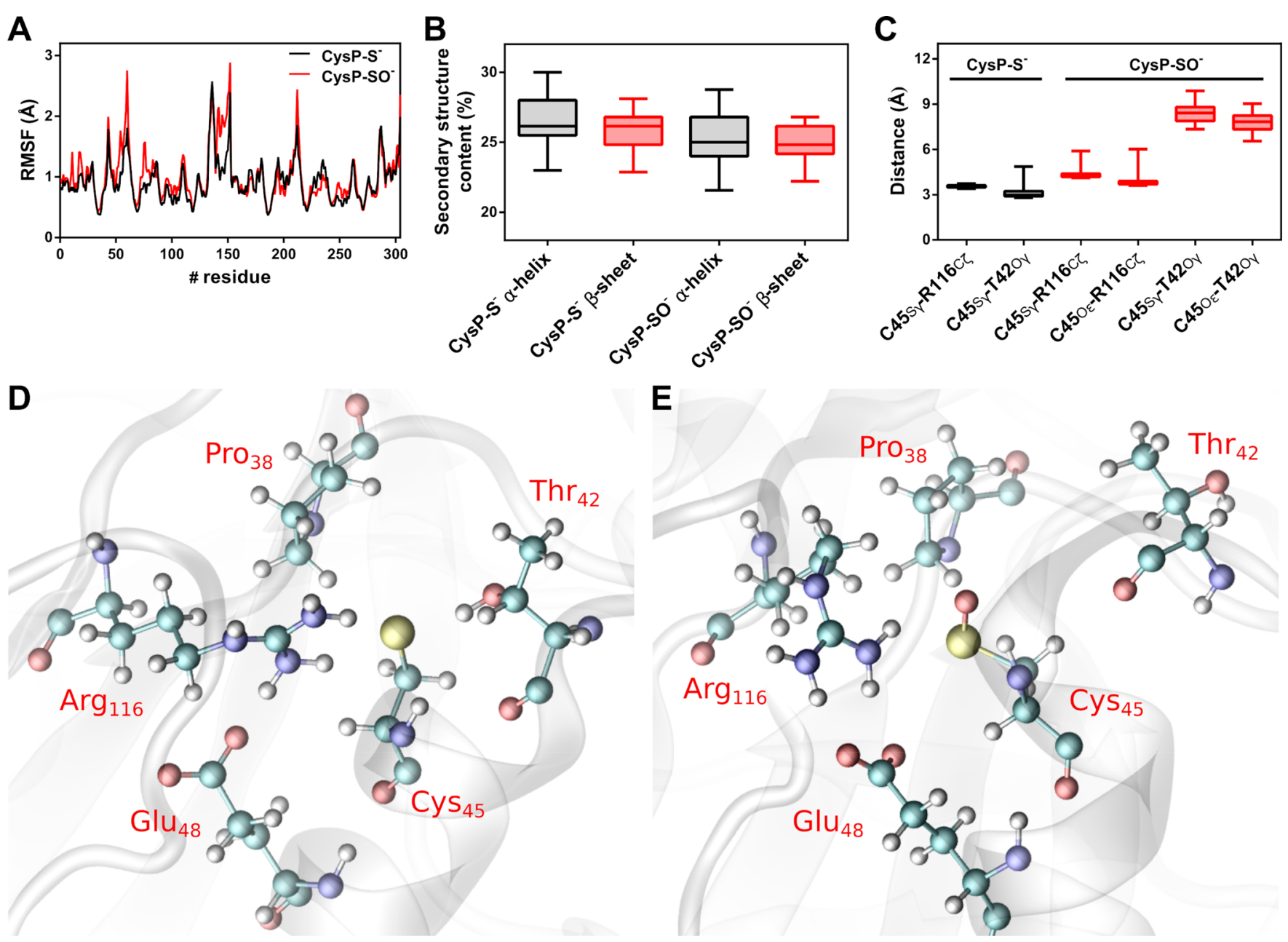

Figure 3. Structural and dynamical comparison of thiolate and sulfenate states of MtAhpE. (A) Root mean square fluctuation ( $\AA$ ) on a per residue basis and (B) secondary structure content (\%) obtained from MD simulations of different redox states. (C) Distribution of relevant distances at the active site $(\AA)$. (D and E) Typical snapshots of MtAhpE active site taken from MD simulations of $\mathrm{Cys}_{\mathrm{p}}-\mathrm{S}^{-}$and $\mathrm{Cys}_{\mathrm{p}}-\mathrm{SO}^{-}$systems, respectively. 

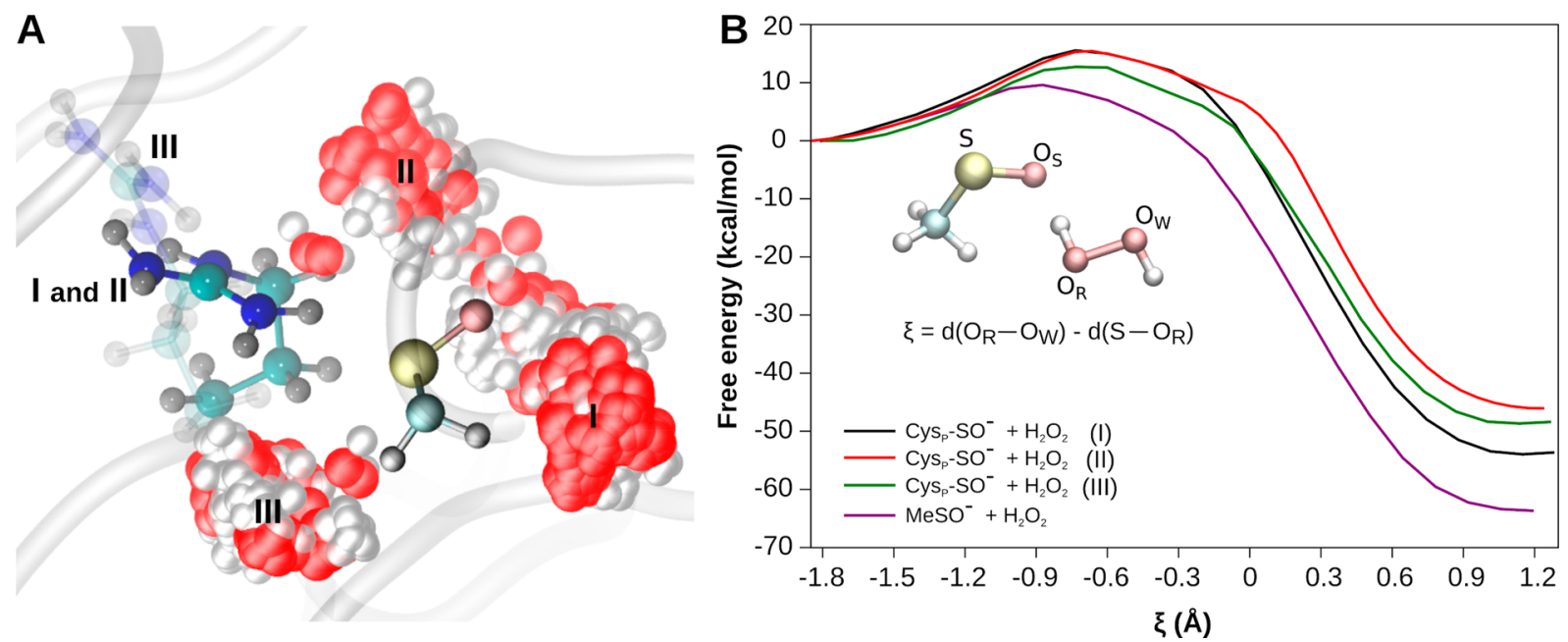

Figure 4. (A) Schematic representation of $\mathrm{H}_{2} \mathrm{O}_{2}$ sampling in $\mathrm{MtAhpE}-\mathrm{Cys} \mathrm{p}_{\mathrm{p}}-\mathrm{SO}^{-}$active site obtained by restrained $\mathrm{MD}$ simulations. Three clusters of $\mathrm{H}_{2} \mathrm{O}_{2}$ positioning with respect to $\mathrm{Cys}_{\mathrm{p}}-\mathrm{SO}^{-}$were observed (I, II, and III; oxygen and hydrogen atoms density depicted in red and gray, respectively). Two conformations of $\mathrm{Arg}_{116}$ are depicted as they depend on $\mathrm{H}_{2} \mathrm{O}_{2}$ locations. (B) Free energy profiles of $\mathrm{H}_{2} \mathrm{O}_{2}$ reduction reactions by $\mathrm{MeSO}^{-}$or $\mathrm{Cys}_{\mathrm{p}}-\mathrm{SO}^{-}$starting from the three different conformations observed in A obtained by QM/MM umbrella sampling simulations. A schematic representation of the QM subsystem and the reaction coordinate $(\xi)$ definition are shown.

408 substrate positioning and thus its interactions with different 409 chemical groups of the enzyme, we decided to determine the 410 overoxidation reaction free energy profile starting from a 411 representative structure of each one, in order to evaluate the 412 consequences of these dynamical characteristics on the 413 reactivity properties of the system.

414 3.2. Reactions Evolution and Mechanism. The free 415 energy profiles and the corresponding free energy barriers $416\left(\Delta G^{\dagger}\right)$ of the studied reactions are shown in Figure 4B and 417 Table 2. Free energy barriers of these reactions are sensitive to

Table 2. Free Energy Barriers for $\mathrm{MeSO}^{-}$and $\mathrm{MtAhpE}-$ Cys $_{\mathrm{P}}-\mathrm{SO}^{-}$Reactions with $\mathrm{H}_{2} \mathrm{O}_{2}$ Obtained by Electronic Structure Calculations or by QM/MM Umbrella Sampling Simulations

\begin{tabular}{|c|c|c|}
\hline reaction & method & $\begin{array}{l}\Delta G^{\dagger}(\mathrm{kcal} / \\
\mathrm{mol})\end{array}$ \\
\hline \multirow[t]{3}{*}{$\mathrm{MeSO}^{-}+\mathrm{H}_{2} \mathrm{O}_{2} \rightarrow \mathrm{MeSO}_{2}^{-}+\mathrm{H}_{2} \mathrm{O}$} & in vacuo/PBE/dzvp & 12 \\
\hline & in vacuo/MP2/dzvp & 24 \\
\hline & $\begin{array}{l}\mathrm{QM} / \mathrm{MM} / \mathrm{PBE} / \mathrm{dzvp} \\
\text { umbrella sampling }\end{array}$ & $9.6 \pm 0.7$ \\
\hline $\begin{array}{l}\mathrm{Cys}_{\mathrm{P}}-\mathrm{SO}^{-}+\mathrm{H}_{2} \mathrm{O}_{2} \rightarrow \mathrm{Cys}_{\mathrm{P}}-\mathrm{SO}_{2}^{-}+ \\
\mathrm{H}_{2} \mathrm{O}(\text { conformation II) }\end{array}$ & $\begin{array}{l}\text { QM/MM/PBE/dzvp } \\
\text { umbrella sampling }\end{array}$ & $16.0 \pm 0.5$ \\
\hline
\end{tabular}

418 the level of theory used and/or to the presence of explicit 419 water molecules in the simulated system, as has been discussed 420 previously. ${ }^{27}$ Except for an earlier transition state (TS) found 421 for the reaction of $\mathrm{MeSO}^{-}$in aqueous solution with respect to 422 the $\mathrm{Cys}_{\mathrm{P}}-\mathrm{SO}^{-}$in the enzyme ( $\xi$ values of -0.9 and $-0.7 \AA$, 423 respectively), no significant changes were observed regarding 424 the operative reaction mechanism: in both enzyme and 425 solution environments, the overoxidation reaction could be 426 described as a bimolecular nucleophilic substitution followed 427 by a proton transfer. Three major processes were observed to 428 describe the evolution of the reaction: the $\mathrm{S}-\mathrm{O}_{\mathrm{R}}$ bond 429 formation, the $\mathrm{O}_{\mathrm{R}}-\mathrm{O}_{\mathrm{W}}$ bond breaking, and the proton transfer 430 from $\mathrm{O}_{R}$ to $\mathrm{O}_{W}$ to yield a water molecule. This mechanistic 431 behavior showed analogies with that of the oxidation of 432 thiolates. ${ }^{4,42,61,78,79}$ Since the proton is transferred after the TS 433 is reached, the selection of the reaction coordinate is expected to have reliable free activation energies, and the reaction free 434 energies might be even lower (more negative) than the ones 435 reported in this work, for which the direct calculation of an 436 equilibrium constant or a redox potential might be prone to 437 large errors. Nevertheless, all the reactions under investigation 438 turn out to be strongly exergonic (being completely 439 irreversible), and errors coming from the lack of sampling of 440 the hydrogen transfer process or from Hamiltonian flaws 441 would not affect the overall trend (Figure 4B).

442

The $\Delta G^{\dagger}$ values (Figure 4B) show that the enzyme 443 microenvironment raises the value of the barrier by $\sim 3-6444$ $\mathrm{kcal} / \mathrm{mol}$ (depending on the starting conformation) compared 445 to the reaction in aqueous solution, which suggests that 446 residues and interactions that are responsible for the oxidation 447 catalysis do not play a catalytic role in the overoxidation 448 reaction. ${ }^{61}$ Additionally, the comparison of the results obtained 449 in vacuo for $\mathrm{MeSO}^{-}$, by means of electronic structure 450 calculations, and those coming from the QM/MM MD 451 shows that the aqueous solvent lowers the barrier and that 452 the PBE functional underestimates the free energy barrier in 453 comparison with the MP2 method, which could be possibly 454 attributed to the flaws of DFT at the GGA level for describing 455 transition states. $^{65,80}$ The TS structures obtained in vacuo 456 (which were confirmed through IRC calculations) and from 457 the $\mathrm{QM} / \mathrm{MM}$ simulations were very similar, supporting the 458 reliability of these results.

Given the exponential dependence of the rate constant on 460 the free energy barrier (due to Eyring's equation ${ }^{81}$ ), even small 461 errors on the latter would lead to large variations in the 462 calculated rate constant, and as shown in Table 2, the 463 electronic structure method strongly affects the absolute value 464 of the computed barriers. However, the ratio between the rate 465 constants of two bimolecular reactions (namely, $k_{1}$ and $k_{2}$ ) can 466 be roughly estimated as $k_{1} / k_{2}=\exp \left(\Delta G_{2}^{\dagger}-\Delta G_{1}^{\dagger}\right)$, assuming 467 compensation of errors in the computed barriers. From the 468 free energy profiles shown in Figure 4, $\mathrm{Cys}_{\mathrm{P}}-\mathrm{SO}^{-}$in 469 conformations I and II (Figure 4) is expected to react $\sim 10^{4} 470$ times slower than $\mathrm{MeSO}^{-}$, while a $\sim 10^{2}$ factor is expected for 471 conformation III. Additionally, the obtained $\Delta G^{\dagger}$ values for the 472 MtAhpE overoxidation are several kilocalories per mole lower 473 

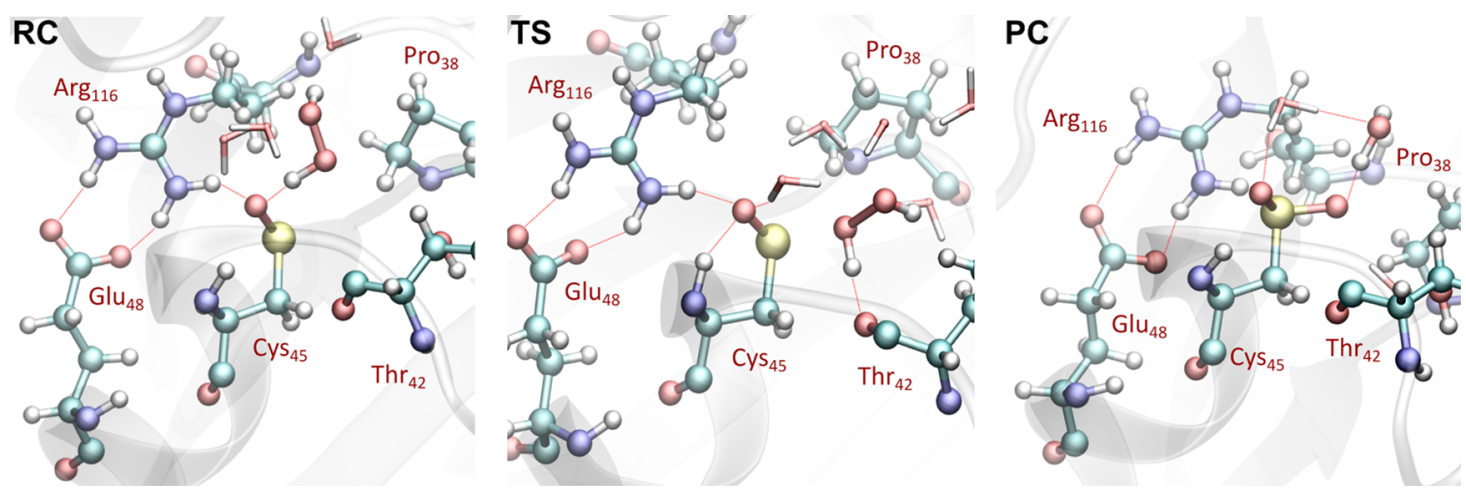

Figure 5. Representative snapshots of reactant complex (RC), transition state (TS), and product complex (PC) for the oxidation of $\mathrm{Cys}_{\mathrm{p}} \mathrm{SO}^{-}$ (conformation II) by $\mathrm{H}_{2} \mathrm{O}_{2}$, obtained by umbrella sampling QM/MM simulations.

474 than the experimentally determined $10.5 \mathrm{kcal} / \mathrm{mol}$ for the 475 oxidation process, ${ }^{61}$ and the same trend is observed when 476 comparing with computationally estimated barriers. ${ }^{4,61}$ These 477 results are in qualitative agreement with the lower second478 order rate constants determined for this reaction in several 479 enzymes (Table 1) in comparison to those of the oxidation 480 process (the oxidation being $\sim 10^{3}$ faster at $25{ }^{\circ} \mathrm{C}$ in the 481 particular case of MtAhpE). ${ }^{12,22,41,61}$

482 On the other hand, the oxidation reaction has been reported 483 to be accelerated $\sim 10^{4}$ times by the enzyme, which in turn 484 emphasizes the unfavorable microenvironment that the 485 enzyme provides for the overoxidation reaction in contrast 486 with the oxidation reaction (in each case, relative to the 487 corresponding reaction in aqueous solution). In our previous 488 study of the oxidation reaction, the exploration of the free 489 energy landscape using the umbrella sampling method allowed 490 us to identify key events during the oxidation reaction, and the 491 obtained $\Delta \Delta G^{\dagger}$ of $\sim 4 \mathrm{kcal} / \mathrm{mol}$ was in reasonable agreement 492 with the 4 orders of magnitude increase in the oxidation rate 493 constants and the experimental $\Delta \Delta G^{\dagger}$ of $5.4 \mathrm{kcal} / \mathrm{mol} .{ }^{61}$ 494 Furthermore, the strong interactions of the thiolate and the 495 peroxide with $\operatorname{Arg} 116$ and $\mathrm{Thr} 42$ residues, which are extremely 496 conserved among the Prx family, confirmed that these are key 497 residues in the stabilization of the TS due to an active site 498 design that sets up a complex H-bond network. This is 499 consistent with the decrease of reactivity with hydrogen 500 peroxide previously measured for MtAhpE variants lacking 501 these residues. ${ }^{82}$ More precisely, Arg116, which is initially 502 oriented to the thiolate with both $\mathrm{N}$ atoms equidistant to the $\mathrm{S}$ 503 atom (see Figure 3D), turns toward one of the $\mathrm{O}$ atoms of the 504 peroxide facilitating the TS linear arrangement and its 505 stabilization through $\mathrm{H}$-bond interactions involving also the $506 \mathrm{Thr} 42$ hydroxyl group. However, when the sulfenate is formed, 507 Arg116 interacts through two H-bonds with Glu48 in 508 conformations I and II (Figure 3E). In conformation III, $509 \operatorname{Arg} 116$ is oriented outward from the active site and interacts 510 with Glu48, forming only one H-bond. The presence of this 511 double H-bond interaction in conformations I and II leads to a 512 different behavior of the Arg116 that practically does not

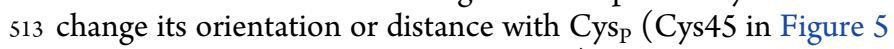
514 and Supporting Information Figure S4) through the reaction. 515 Only conformation III exhibits some mobility in Arg116 but 516 always maintains its position far from the active site.

517 Taking into account that the TS structure turned out to be 518 qualitatively the same for the three conformations studied and 519 for the reaction in solution, we further investigate if the 520 differences in the free energy barriers could be related not to significant changes in the TS structure but to the differential 521 stabilization of the RC and TS in each case.

3.3. Charges Distribution and Solvation Patterns 523 Evolution. Regarding nucleophilic substitutions, free energy 524 barriers can be interpreted in terms of charges redistribution 525 since the reaction is driven by the tendency of the electrophile 526 to become more negative. In this work, we monitored the 527 charge redistribution by means of Mulliken's populations over 528 relevant atoms along the reaction, by computing the average 529 values for each umbrella sampling window (see Figures 6 and $530 \mathrm{fo}$

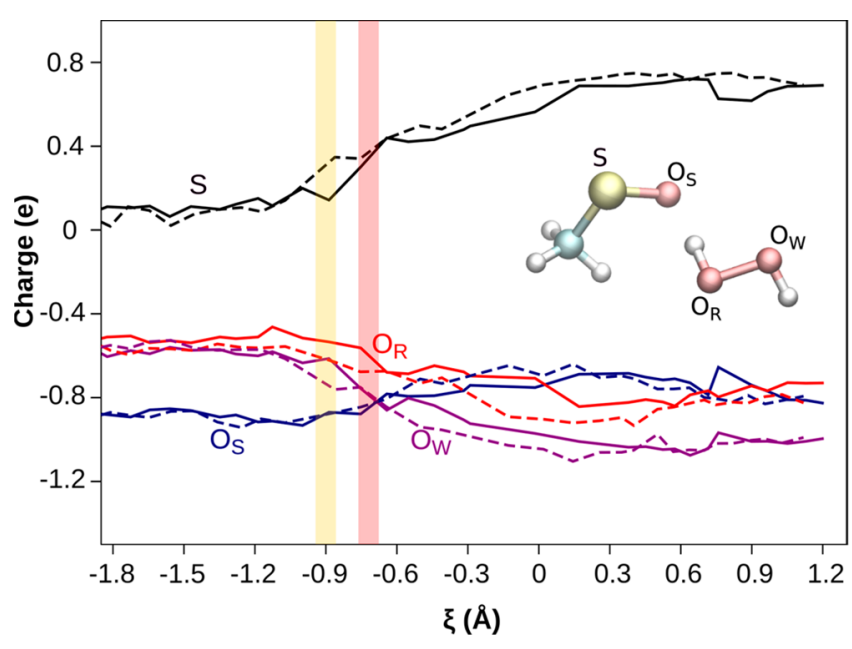

Figure 6. Mulliken charge evolution for the reaction of $\mathrm{H}_{2} \mathrm{O}_{2}$ with $\mathrm{MeSO}^{-}$and MtAhpE-Cys $\mathrm{p}^{-} \mathrm{SO}^{-}$in conformation II (dashed and solid lines, respectively). The reaction coordinate values corresponding to the TS regions are indicated by a yellow and a red box for the reaction in aqueous solution and protein, respectively. Labels are shown on a representative snapshot of the QM subsystem.

Supporting Information Figure S5). In general, evolution of 531 charges is quite similar between the reaction in solution and in 532 the enzymatic environment, being practically identical among 533 the three conformations. At the same time that the $\mathrm{S}$ atom 534 becomes more positive, its charge is transferred to both $\mathrm{O}_{\mathrm{R}}$ and 535 $\mathrm{O}_{\mathrm{W}}$ atoms of hydrogen peroxide. The $\mathrm{O}_{\mathrm{S}}$ atom's charge, on the 536 other hand, remains almost unmodified from the RC to the TS. 537 In the oxidation reaction, the enzyme provides a set of 538 interactions described above which carefully guides this 539 process, allowing the charge redistribution to take place at a 540 lower energy cost compared to the reaction in aqueous 541 solution. The opposite effect is observed in the overoxidation 542 
543 process, where the amount of charge transferred at around $544-0.9 \AA$ of the reaction coordinate (corresponding to TS for the 545 reaction in solution, yellow box in Figure 6) is lower than that 546 of the enzyme, at the same reaction coordinate value. In other 547 words, at the same stage of the reaction, the $S$ atom is more 548 positive, and $\mathrm{O}_{\mathrm{R}}$ and $\mathrm{O}_{\mathrm{W}}$ are more negative in the reaction in 549 solution than in the enzyme. Interestingly, in the enzyme, once 550 the TS is reached, charges coincide approximately to those of 551 the TS in solution, which suggests that the free energy reaches 552 its maximum only once a certain amount of charge gets 553 distributed. The charge transfer from the nucleophilic center 554 (the $S$ atom) to the hydroperoxide is achieved more easily (at 555 an earlier reaction coordinate value and with a lower free 556 energy cost) in aqueous solution than in this enzyme 557 microenvironment.

558 An interesting issue is how water molecules facilitate the 559 charge distribution needed in order to reach the TS and so 560 overcome the reaction free energy barrier. With the aim of 561 answering this question, we computed radial correlation 562 functions $(g(\mathrm{r}))$ centered in selected atoms with respect to 563 oxygen water molecules at different stages of the reaction (see 564 Figures 7 and Supporting Information Figure S3). Typically, 565 the first solvation shell (given by the first peak of the radial 566 correlation function) is centered between $\sim 2.7$ and $3.0 \AA$ 567 (radial distance) for oxygen atoms, while the $S$ atom practically 568 lacks a solvation structure. More importantly, both in enzyme
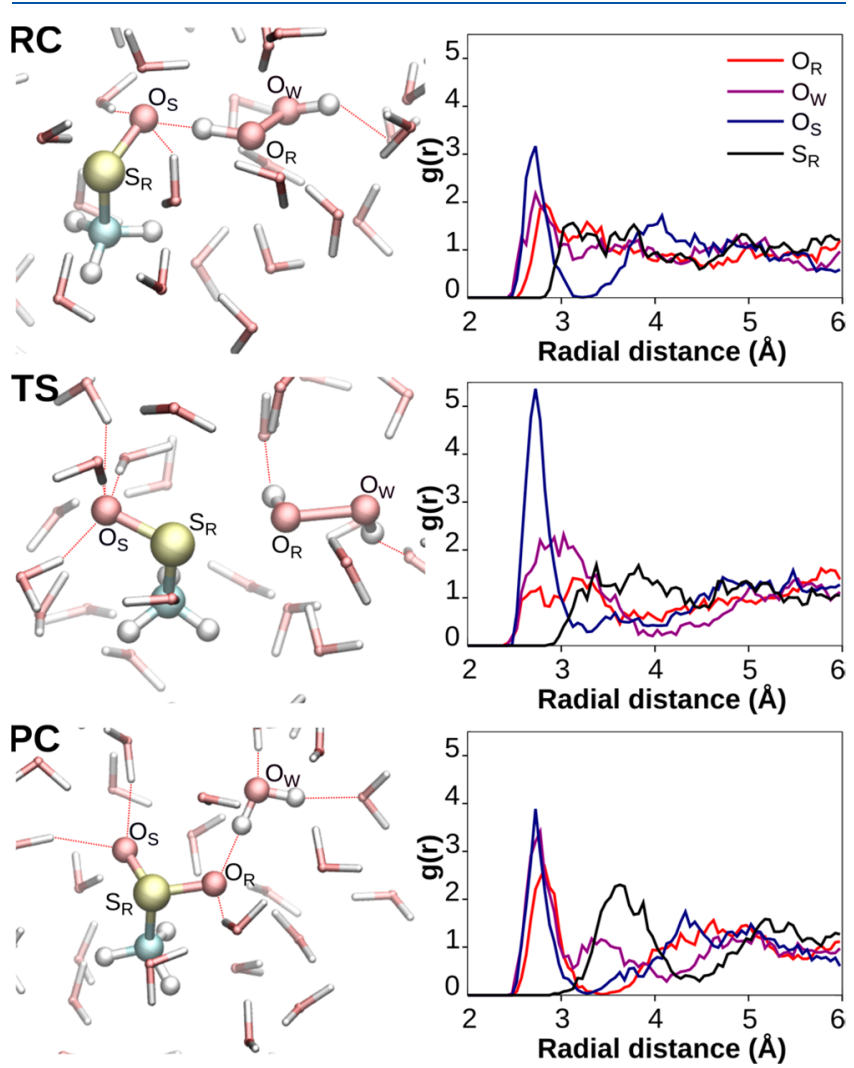

Figure 7. Left: Representative snapshots of reactant complex (RC), transition state (TS), and product complex (PC) for the oxidation of $\mathrm{MeSO}^{-}$by $\mathrm{H}_{2} \mathrm{O}_{2}$ in aqueous solution, obtained by umbrella sampling $\mathrm{QM} / \mathrm{MM}$ simulation. Bond interactions within centers closer than 2 $\AA$ are depicted. Right: Corresponding radial correlation functions for selected atoms with respect to MM water oxygen atoms obtained by performing 50 ps $\mathrm{QM} / \mathrm{MM}$ sampling with the stochastic Langevin thermostat model. reactions and in solution reactions, the $\mathrm{O}_{S}$ atom is pointing to 569 the $\mathrm{O}_{\mathrm{R}}$ atom from the hydroperoxide at RC, while in the TS an 570 $\mathrm{O}_{\mathrm{S}}-\mathrm{S}-\mathrm{O}_{\mathrm{R}}$ angle is slightly larger than $90^{\circ}$ (see Figures 5 and 571 7 ), allowing the $\mathrm{O}_{S}$ atom to be fully solvated. Therefore, even 572 though the charge on the $\mathrm{O}_{\mathrm{S}}$ atom does not change 573 significantly from RC to TS, it becomes significantly more 574 solvated at the TS, as reflected in the increase of the $\mathrm{O}_{\mathrm{S}} g(r) 575$ first peak for the reaction in solution (Figure 7).

In the enzymatic environment, other residues, like Arg116 577 (conformation I and II, Figure 4), interact with $\mathrm{O}_{\mathrm{S}}$ at the TS, 578 replacing the solvent molecules, and solvation patterns remain 579 almost unaffected from RC to TS (see Supporting Information 580 Figure S3). The only exception is conformation III, in which 581 the different orientation of Arg116 allows the entrance of more 582 water molecules into the active site, and particularly the $\mathrm{O}_{\mathrm{W}} 583$ atom becomes more solvated at the TS. These differences in 584 solvation patterns between RC and TS account for the 585 observed tendency in the free energy profiles: the more 586 efficiently the TS is solvated, compared to the RC, the lower 587 the free energy barrier. Finally, these results also suggest that 588 there is no specific stabilization of the RC or TS provided by 589 residues of the active site, since the differential solvation 590 rationale seems to account for all the observed differences 591 between the free energy barriers of the reaction in solution and 592 in the enzyme and between the three enzyme conformations 593 studied.

594

\section{CONCLUSIONS}

A multiscale study of the $\mathrm{H}_{2} \mathrm{O}_{2}$-mediated oxidation of 595 sulfenates either in a LMW compound as well as in a 596 peroxidatic cysteine residue was performed. MtAhpE-Cys $\mathrm{P}^{-} 597$ $\mathrm{SO}^{-}$and $\mathrm{MeSO}^{-}$were selected as examples and free energy 598 profiles calculations by means of the umbrella sampling 599 method, which allowed us to estimate free energy barriers as 600 well as mechanistic information and evolution of key 601 properties through the process for each case.

602

In the case of MtAhpE-Cys ${ }_{\mathrm{P}}-\mathrm{SO}^{-}$, we analyzed and 603 compared three different starting conformations obtained by 604 relatively long classical simulations of the enzyme with a $\mathrm{H}_{2} \mathrm{O}_{2} 605$ molecule restrained close to its active site. These conforma- 606 tions differed mainly on the orientation of $\mathrm{H}_{2} \mathrm{O}_{2}$ and $\mathrm{Arg} 116$, a 607 strictly conserved residue in this enzyme family and actively 608 contributing in the oxidation step of the catalytic cycle. The 609 different interaction network at the active site was useful for 610 understanding the influence of certain residues and solvent 611 molecules in the free energy barriers obtained. In comparison 612 with the reaction in solution, our results suggest that the 613 MtAhpE environment does not accelerate the overoxidation 614 process by hydrogen peroxide. The possible role of protein 615 microenvironment in overoxidation caused by other hydro- 616 peroxides such as fatty acid hydroperoxides, that are not only 617 highly efficient substrates for this enzyme but also rapidly 618 inactivate it through overoxidation, ${ }^{29,42}$ should be a matter of 619 further investigation. Moreover, the free energy barriers 620 showed that overoxidation is unfavored by the enzyme, 621 which can be related to a better stabilization of the TS in 622 aqueous solution because of a significant increase in the local 623 solvation of $\mathrm{O}_{\mathrm{S}}$ with respect to the RC stage. In this context, 624 the advantages of the QM/MM approach, which allowed us to 625 explore the free energy landscape including explicitly the 626 solvent water molecules at an affordable cost, are highlighted. 627 Finally, free energy profiles allowed us to obtain not only 628 mechanistic information but also kinetic and thermodynamic 629 
630 properties that could be directly compared with experimental 631 data for validating the methodology. In addition, we have 632 shown that properties such as the evolution of charge 633 distribution, solvation patterns, and geometric parameters 634 that cannot be easily assessed experimentally can be estimated 635 quite directly from the simulations and offer useful information 636 for the understanding of the reactive processes in complex 637 environments.

\section{ASSOCIATED CONTENT}

639 S Supporting Information

640 The Supporting Information is available free of charge at 641 https://pubs.acs.org/doi/10.1021/acs.jcim.9b00817.

642 Figures $\mathrm{S} 1-\mathrm{S} 5$ (PDF)

\section{AUTHOR INFORMATION}

\section{Corresponding Authors}

645 *E-mail: azeida@fmed.edu.uy.

646 *E-mail: dario@qi.fcen.uba.ar.

647 ORCID $\odot$

648 R. Radi: 0000-0002-1114-1875

649 D. A. Estrin: 0000-0002-5006-7225

650 Notes

651 The authors declare no competing financial interest.

\section{ACKNOWLEDGMENTS}

653 J.S. is supported by doctoral fellowship from Consejo Nacional 654 de Investigaciones Cientificas y Técnicas (CONICET). J.S. 655 and D.A.E. gratefully acknowledge the funding from 656 Universidad de Buenos Aires (UBACYT 657 20020130100097BA) and Agencia Nacional de Promoción 658 Científica y Tecnológica (PICT 2014-1022, and PICT 2015659 2761) and CONICET Grant 11220150100303 CO. F.B. was 660 supported by a Santander Ibero-America grant. A.Z. is 661 supported by a posdoctoral fellowship from Agencia Nacional 662 de Investigación e Innovación (ANII), Uruguay. R.R., M.T., 663 and A.Z. are grateful for funding from Comisión Sectorial de 664 Investigación Científica (CSIC I+D 2016 to M.T. and CSIC 665 Grupos 2018 to R.R.); Espacio Interdisciplinario (Cen666 tros_2015 to R.R.); Universidad de la República, Ministerio 667 de Educación y Cultura (Fondo Vaz Ferreira 2018 to A.Z.), 668 Uruguay; Centro de Biología Estructural Mercosur (CeBEM); 669 Centro de Computación de Alto Rendimiento (CeCAR) de la 670 Facultad de Ciencias Exactas y Naturales de la UBA; and 671 Programa de Desarrollo de Ciencias Básicas (PEDECIBA), 672 Uruguay.

\section{$673 \square$ REFERENCES}

674 (1) Crespo, A.; Scherlis, D. A.; Martí, M. A.; Ordejón, P.; Roitberg, 675 A. E.; Estrin, D. A. A DFT-Based QM-MM Approach Designed for 676 the Treatment of Large Molecular Systems: Application to 677 Chorismate Mutase. J. Phys. Chem. B 2003, 107, 13728-13736.

678 (2) Crespo, A.; Martí, M. A.; Kalko, S. G.; Morreale, A.; Orozco, M.; 679 Gelpi, J. L.; Luque, F. J.; Estrin, D. A. Theoretical Study of the 680 Truncated Hemoglobin HbN: Exploring the Molecular Basis of the 681 NO Detoxification Mechanism. J. Am. Chem. Soc. 2005, 127, 44336824444

683 (3) Lewis-Ballester, A.; Batabyal, D.; Egawa, T.; Lu, C.; Lin, Y.; 684 Marti, M. A.; Capece, L.; Estrin, D. A.; Yeh, S.-R. Evidence for a 685 Ferryl Intermediate in a Heme-Based Dioxygenase. Proc. Natl. Acad. 686 Sci. U. S. A. 2009, 106, 17371-17376.

687 (4) Marcolongo, J. P.; Zeida, A.; Semelak, J. A.; Foglia, N. O.; 688 Morzan, U. N.; Estrin, D. A.; González Lebrero, M. C.; Scherlis, D. A.
Chemical Reactivity and Spectroscopy Explored From QM/MM 689 Molecular Dynamics Simulations Using the LIO Code. Front. Chem. 690 2018, 6, DOI: $10.3389 /$ fchem.2018.00070.

(5) Nitsche, M. A.; Ferreria, M.; Mocskos, E. E.; González Lebrero, 692 M. C. GPU Accelerated Implementation of Density Functional 693 Theory for Hybrid QM/MM Simulations. J. Chem. Theory Comput. 694 2014, 10, 959-967.

(6) Joseph, C. A.; Maroney, M. J. Cysteine Dioxygenase: Structure 696 and Mechanism. Chem. Commun. 2007, 3338-3349.

(7) Akter, S.; Fu, L.; Jung, Y.; Conte, M. L.; Lawson, J. R.; Lowther, 698 W. T.; Sun, R.; Liu, K.; Yang, J.; Carroll, K. S. Chemical Proteomics 699 Reveals New Targets of Cysteine Sulfinic Acid Reductase. Nat. Chem. 700 Biol. 2018, 14, 995-1004.

(8) Lee, C.-F.; Paull, T. T.; Person, M. D. Proteome-Wide Detection 702 and Quantitative Analysis of Irreversible Cysteine Oxidation Using 703 Long Column UPLC-PSRM. J. Proteome Res. 2013, 12, 4302-4315. 704

(9) Hamann, M.; Zhang, T.; Hendrich, S.; Thomas, J. A. [15] 705 Quantitation of Protein Sulfinic and Sulfonic Acid, Irreversibly 706 Oxidized Protein Cysteine Sites in Cellular Proteins. In Methods in 707 Enzymology; Elsevier, 2002; Vol. 348, pp 146-156. 708

(10) Jacob, C.; Holme, A. L.; Fry, F. H. The Sulfinic Acid Switch in 709 Proteins. Org. Biomol. Chem. 2004, 2, 1953-1956. 710

(11) Yang, K.-S.; Kang, S. W.; Woo, H. A.; Hwang, S. C.; Chae, H. 711 Z.; Kim, K.; Rhee, S. G. Inactivation of Human Peroxiredoxin I during 712 Catalysis as the Result of the Oxidation of the Catalytic Site Cysteine 713 to Cysteine-Sulfinic Acid. J. Biol. Chem. 2002, 277, 38029-38036. 714

(12) Trujillo, M.; Alvarez, B.; Radi, R. One-and Two-Electron 715 Oxidation of Thiols: Mechanisms, Kinetics and Biological Fates. Free 716 Radical Res. 2016, 50, 150-171.

(13) Sevilla, M.; Becker, D.; Yan, M. The Formation and Structure 718 of the Sulfoxyl Radicals RSO., RSOO., $\mathrm{RSO}_{2}$, and $\mathrm{RSO}_{2} \mathrm{OO}$. from 719 the Reaction of Cysteine, Glutathione and Penicillamine Thiyl 720 Radicals with Molecular Oxygen. Int. J. Radiat. Biol. 1990, 57, 65-81. 721

(14) Xu, G.; Chance, M. R. Radiolytic Modification of Sulfur- 722 Containing Amino Acid Residues in Model Peptides: Fundamental 723 Studies for Protein Footprinting. Anal. Chem. 2005, 77, 2437-2449. 724

(15) Winterbourn, C. C. Biological Production, Detection, and Fate 725 of Hydrogen Peroxide. Antioxid. Redox Signaling 2018, 29, 541-551. 726

(16) Rhee, S. G. A Catalytic Career: Studies Spanning Glutamine 727 Synthetase, Phospholipase C, Peroxiredoxin, and the Intracellular 728 Messenger Role of Hydrogen Peroxide. J. Biol. Chem. 2019, 294, 729 5169-5180.

(17) Winterbourn, C. C.; Metodiewa, D. Reactivity of Biologically 731 Important Thiol Compounds with Superoxide and Hydrogen 732 Peroxide. Free Radical Biol. Med. 1999, 27, 322-328. 733

(18) Portillo-Ledesma, S.; Sardi, F.; Manta, B.; Tourn, M. V.; Clippe, 734 A.; Knoops, B.; Alvarez, B.; Coitiño, E. L.; Ferrer-Sueta, G. 735 Deconstructing the Catalytic Efficiency of Peroxiredoxin-5 Peroxidatic 736 Cysteine. Biochemistry 2014, 53, 6113-6125.

(19) Poole, L. The Catalytic Mechanism of Peroxiredoxins. In 738 Peroxiredoxin Systems; Flohé, L., Harris, J. R., Eds.; Subcellular 739 Biochemistry, Springer, New York, 2007.

(20) Perkins, A.; Nelson, K. J.; Parsonage, D.; Poole, L. B.; Karplus, 741 P. A. Peroxiredoxins: Guardians against Oxidative Stress and 742 Modulators of Peroxide Signaling. Trends Biochem. Sci. 2015, 40, 743 435-445.

744

(21) Flohé, L.; Toppo, S.; Cozza, G.; Ursini, F. A Comparison of 745 Thiol Peroxidase Mechanisms. Antioxid. Redox Signaling 2011, 15, 746 $763-780$.

747

(22) Zeida, A.; Trujillo, M.; Ferrer-Sueta, G.; Denicola, A.; Estrin, D. 748 A.; Radi, R. Catalysis of Peroxide Reduction by Fast Reacting Protein 749 Thiols. Chem. Rev. 2019, 119, 10829.

750

(23) Lo Conte, M.; Carroll, K. S. The Redox Biochemistry of 751 Protein Sulfenylation and Sulfinylation. J. Biol. Chem. 2013, 288, 752 26480-26488.

753

(24) Abedinzadeh, Z.; Gardes-Albert, M.; Ferradini, C. Kinetic study 754 of the oxidation mechanism of glutathione by hydrogen peroxide in 755 neutral aqueous medium. Can. J. Chem. 1989, 67, 1247-1255. 756 
757 (25) Chauvin, J.-P. R.; Pratt, D. A. On the Reactions of Thiols, 758 Sulfenic Acids, and Sulfinic Acids with Hydrogen Peroxide. Angew. 759 Chem., Int. Ed. 2017, 56 (22), 6255-6259.

760 (26) Hugo, M.; Turell, L.; Manta, B.; Botti, H.; Monteiro, G.; Netto, 761 L. E.; Alvarez, B.; Radi, R.; Trujillo, M. Thiol and Sulfenic Acid 762 Oxidation of AhpE, the One-Cysteine Peroxiredoxin from Myco763 bacterium Tuberculosis: Kinetics, Acidity Constants, and Conforma764 tional Dynamics. Biochemistry 2009, 48, 9416-9426.

765 (27) van Bergen, L. A.; Roos, G.; De Proft, F. From Thiol to 766 Sulfonic Acid: Modeling the Oxidation Pathway of Protein Thiols by 767 Hydrogen Peroxide. J. Phys. Chem. A 2014, 118, 6078-6084.

768 (28) Rabilloud, T.; Heller, M.; Gasnier, F.; Luche, S.; Rey, C.; 769 Aebersold, R.; Benahmed, M.; Louisot, P.; Lunardi, J. Proteomics 770 Analysis of Cellular Response to Oxidative Stress Evidence for in Vivo 771 Overoxidation of Peroxiredoxins at Their Active Site. J. Biol. Chem. 772 2002, 277, 19396-19401.

773 (29) Reyes, A. M.; Hugo, M.; Trostchansky, A.; Capece, L.; Radi, R.; 774 Trujillo, M. Oxidizing Substrate Specificity of Mycobacterium 775 Tuberculosis Alkyl Hydroperoxide Reductase E: Kinetics and 776 Mechanisms of Oxidation and Overoxidation. Free Radical Biol. 777 Med. 2011, 51, 464-473.

778 (30) Peskin, A. V.; Dickerhof, N.; Poynton, R. A.; Paton, L. N.; Pace, 779 P. E.; Hampton, M. B.; Winterbourn, C. C. Hyperoxidation of 780 Peroxiredoxins 2 and 3: Rate Constants for the Reactions of the 781 Sulfenic Acid of the Peroxidatic Cysteine. J. Biol. Chem. 2013, 288, $782 \quad 14170-14177$

783 (31) Karplus, P. A. A Primer on Peroxiredoxin Biochemistry. Free 784 Radical Biol. Med. 2015, 80, 183-190.

785 (32) Wood, Z. A.; Poole, L. B.; Karplus, P. A. Peroxiredoxin 786 Evolution and the Regulation of Hydrogen Peroxide Signaling. Science 787 2003, 300, 650-653.

788 (33) Song, I.-K.; Lee, J.-J.; Cho, J.-H.; Jeong, J.; Shin, D.-H.; Lee, K.$789 \mathrm{~J}$. Degradation of Redox-Sensitive Proteins Including Peroxiredoxins 790 and DJ-1 Is Promoted by Oxidation-Induced Conformational 791 Changes and Ubiquitination. Sci. Rep. 2016, 6, 34432.

792 (34) Chang, T.-S.; Jeong, W.; Woo, H. A.; Lee, S. M.; Park, S.; Rhee, 793 S. G. Characterization of Mammalian Sulfiredoxin and Its 794 Reactivation of Hyperoxidized Peroxiredoxin through Reduction of 795 Cysteine Sulfinic Acid in the Active Site to Cysteine. J. Biol. Chem. 796 2004, 279, 50994-51001.

797 (35) Nelson, K. J.; Perkins, A.; Van Swearingen, A. E. D.; Hartman, 798 S.; Brereton, A. E.; Parsonage, D.; Salsbury, F. R.; Karplus, P. A.; 799 Poole, L. B. Experimentally Dissecting the Origins of Peroxiredoxin 800 Catalysis. Antioxid. Redox Signaling 2018, 28, 521-536.

801 (36) Salsbury, F. R.; Yuan, Y.; Knaggs, M. H.; Poole, L. B.; Fetrow, J. 802 S. Structural and Electrostatic Asymmetry at the Active Site in Typical 803 and Atypical Peroxiredoxin Dimers. J. Phys. Chem. B 2012, 116, $8046832-6843$.

805 (37) Yuan, Y.; Knaggs, M. H.; Poole, L. B.; Fetrow, J. S.; Salsbury, F. 806 R. Conformational and Oligomeric Effects on the Cysteine PK(a) of 807 Tryparedoxin Peroxidase. J. Biomol. Struct. Dyn. 2010, 28, 51-70.

808 (38) Wang, X.; Wang, L.; Wang, X.; Sun, F.; Wang, C. Structural 809 Insights into the Peroxidase Activity and Inactivation of Human 810 Peroxiredoxin 4. Biochem. J. 2012, 441, 113-118.

811 (39) Randall, L.; Manta, B.; Nelson, K. J.; Santos, J.; Poole, L. B.; 812 Denicola, A. Structural Changes upon Peroxynitrite-Mediated 813 Nitration of Peroxiredoxin 2; Nitrated Prx2 Resembles Its Disulfide814 Oxidized Form. Arch. Biochem. Biophys. 2016, 590, 101-108.

815 (40) Noichri, Y.; Palais, G.; Ruby, V.; D’Autreaux, B.; Delaunay816 Moisan, A.; Nyström, T.; Molin, M.; Toledano, M. B. In Vivo 817 Parameters Influencing 2-Cys Prx Oligomerization: The Role of 818 Enzyme Sulfinylation. Redox Biol. 2015, 6, 326-333.

819 (41) Hugo, M.; Van Laer, K.; Reyes, A. M.; Vertommen, D.; 820 Messens, J.; Radi, R.; Trujillo, M. Mycothiol/Mycoredoxin 1821 Dependent Reduction of the Peroxiredoxin AhpE from Mycobacte822 rium Tuberculosis. J. Biol. Chem. 2014, 289, 5228-5239.

823 (42) Zeida, A.; Reyes, A. M.; Lichtig, P.; Hugo, M.; Vazquez, D. S.; 824 Santos, J.; González Flecha, F. L.; Radi, R.; Estrin, D. A.; Trujillo, M. 825 Molecular Basis of Hydroperoxide Specificity in Peroxiredoxins: The
Case of AhpE from Mycobacterium Tuberculosis. Biochemistry 2015, 826 54, 7237-7247.

827

(43) Cuevasanta, E.; Reyes, A. M.; Zeida, A.; Mastrogiovanni, M.; 828 De Armas, M. I.; Radi, R.; Alvarez, B.; Trujillo, M. Kinetics of 829 Formation and Reactivity of the Persulfide in the One-Cysteine 830 Peroxiredoxin from Mycobacterium Tuberculosis. J. Biol. Chem. 2019, 831 294, 13593.

(44) Dalla Rizza, J.; Randall, L. M.; Santos, J.; Ferrer-Sueta, G.; 833 Denicola, A. Differential Parameters between Cytosolic 2-Cys 834 Peroxiredoxins, PRDX1 and PRDX2. Protein Sci. 2019, 28, 191-201. 835

(45) Stone, J. R. An Assessment of Proposed Mechanisms for 836 Sensing Hydrogen Peroxide in Mammalian Systems. Arch. Biochem. 837 Biophys. 2004, 422, 119-124.

(46) Peskin, A. V.; Pace, P. E.; Winterbourn, C. C. Enhanced 839 Hyperoxidation of Peroxiredoxin 2 and Peroxiredoxin 3 in the 840 Presence of Bicarbonate/CO2. Free Radical Biol. Med. 2019, 145, 1. 841

(47) De Armas, M. I.; Esteves, R.; Viera, N.; Reyes, A. M.; 842 Mastrogiovanni, M.; Alegria, T. G. P.; Netto, L. E. S.; Tórtora, V.; 843 Radi, R.; Trujillo, M. Rapid Peroxynitrite Reduction by Human 844 Peroxiredoxin 3: Implications for the Fate of Oxidants in 845 Mitochondria. Free Radical Biol. Med. 2019, 130, 369-378. 846

(48) Alvarez, B.; Carballal, S.; Turell, L.; Radi, R. Chapter 5 - 847 Formation and Reactions of Sulfenic Acid in Human Serum Albumin. 848 In Methods in Enzymology; Cadenas, E., Packer, L., Eds.; Thiol Redox 849 Transitions in Cell Signaling, Part A: Chemistry and Biochemistry of 850 Low Molecular Weight and Protein Thiols, Academic Press, 2010; 851 Vol. 473, pp 117-136.

(49) Sohn, J.; Rudolph, J. Catalytic and Chemical Competence of 853 Regulation of $\mathrm{Cdc} 25$ Phosphatase by Oxidation/Reduction. Bio- 854 chemistry 2003, 42, 10060-10070.

(50) Poole, L. B.; Claiborne, A. The Non-Flavin Redox Center of 856 the Streptococcal NADH Peroxidase. II. Evidence for a Stabilized 857 Cysteine-Sulfenic Acid. J. Biol. Chem. 1989, 264, 12330-12338. 858

(51) Crane, E. J.; Parsonage, D.; Claiborne, A. The Active-Site 859 Histidine-10 of Enterococcal NADH Peroxidase Is Not Essential for 860 Catalytic Activity. Biochemistry 1996, 35, 2380.

861

(52) Li, S.; Peterson, N. A.; Kim, M.-Y.; Kim, C.-Y.; Hung, L.-W.; 862 Yu, M.; Lekin, T.; Segelke, B. W.; Lott, J. S.; Baker, E. N. Crystal 863 Structure of AhpE from Mycobacterium Tuberculosis, a 1-Cys 864 Peroxiredoxin. J. Mol. Biol. 2005, 346, 1035-1046. 865

(53) van Bergen, L. A. H.; Alonso, M.; Palló, A.; Nilsson, L.; De 866 Proft, F.; Messens, J. Revisiting Sulfur H-Bonds in Proteins: The 867 Example of Peroxiredoxin AhpE. Sci. Rep. 2016, 6, 30369.

(54) Jorgensen, W. L.; Chandrasekhar, J.; Madura, J. D.; Impey, R. 869 W.; Klein, M. L. Comparison of Simple Potential Functions for 870 Simulating Liquid Water. J. Chem. Phys. 1983, 79, 926-935. 871

(55) Maier, J. A.; Martinez, C.; Kasavajhala, K.; Wickstrom, L.; 872 Hauser, K. E.; Simmerling, C. Ff14SB: Improving the Accuracy of 873 Protein Side Chain and Backbone Parameters from Ff99SB. J. Chem. 874 Theory Comput. 2015, 11, 3696-3713.

(56) Wang, J.; Wolf, R. M.; Caldwell, J. W.; Kollman, P. A.; Case, D. 876 A. Development and Testing of a General Amber Force Field. J. 877 Comput. Chem. 2004, 25, 1157-1174.

(57) Ryckaert, J.-P.; Ciccotti, G.; Berendsen, H. J. C. Numerical 879 Integration of the Cartesian Equations of Motion of a System with 880 Constraints: Molecular Dynamics of n-Alkanes. J. Comput. Phys. 1977, 881 23, 327-341.

(58) Schneider, T.; Stoll, E. Molecular-Dynamics Study of a Three- 883 Dimensional One-Component Model for Distortive Phase Tran- 884 sitions. Phys. Rev. B: Condens. Matter Mater. Phys. 1978, 17, 1302- 885 1322.

(59) Feller, S. E.; Zhang, Y.; Pastor, R. W.; Brooks, B. R. Constant 887 Pressure Molecular Dynamics Simulation: The Langevin Piston 888 Method. J. Chem. Phys. 1995, 103, 4613-4621.

(60) Berendsen, H. J.; Postma, J. P. M.; van Gunsteren, W. F.; 890 DiNola, A.; Haak, J. Molecular Dynamics with Coupling to an 891 External Bath. J. Chem. Phys. 1984, 81, 3684-3690. 892

(61) Zeida, A.; Reyes, A. M.; Lebrero, M. C. G.; Radi, R.; Trujillo, 893 M.; Estrin, D. A. The Extraordinary Catalytic Ability of Peroxiredox- 894 
895 ins: A Combined Experimental and QM/MM Study on the Fast Thiol 896 Oxidation Step. Chem. Commun. 2014, 50, 10070-10073.

897 (62) Frisch, M.; Trucks, G.; Schlegel, H.; Scuseria, G.; Robb, M.; 898 Cheeseman, J.; Scalmani, G.; Barone, V.; Mennucci, B.; Petersson, G. 899 Gaussian 09; Gaussian Inc.: Wallingford, CT, 2009.

900 (63) Godbout, N.; Salahub, D. R.; Andzelm, J.; Wimmer, E. 901 Optimization of Gaussian-Type Basis Sets for Local Spin Density 902 Functional Calculations. Part I. Boron through Neon, Optimization 903 Technique and Validation. Can. J. Chem. 1992, 70, 560-571.

904 (64) Fukui, K. The path of chemical reactions-the IRC approach. 905 Acc. Chem. Res. 1981, 14, 363-368.

906 (65) Neves, R. P.; Fernandes, P. A.; Varandas, A. J.; Ramos, M. J. 907 Benchmarking of Density Functionals for the Accurate Description of 908 Thiol-Disulfide Exchange. J. Chem. Theory Comput. 2014, 10, 48429094856

910 (66) Nitsche, M. A.; Ferreria, M.; Mocskos, E. E.; Gonzalez Lebrero, 911 M. C. GPU Accelerated Implementation of Density Functional 912 Theory for Hybrid QM/MM Simulations. J. Chem. Theory Comput. 913 2014, 10, 959-967.

914 (67) Humphrey, W.; Dalke, A.; Schulten, K. VMD: Visual Molecular 915 Dynamics. J. Mol. Graphics 1996, 14, 33-38.

916 (68) Kumar, S.; Rosenberg, J. M.; Bouzida, D.; Swendsen, R. H.; 917 Kollman, P. A. The Weighted Histogram Analysis Method for Free918 Energy Calculations on Biomolecules. I. The Method. J. Comput. 919 Chem. 1992, 13, 1011-1021.

920 (69) Kastner, J. Umbrella Sampling. Wiley Interdiscip. Rev. Comput. 921 Mol. Sci. 2011, 1, 932-942.

922 (70) Branduardi, D.; Gervasio, F. L.; Parrinello, M. From A to B in 923 Free Energy Space. J. Chem. Phys. 2007, 126, 054103.

924 (71) Peters, B.; Beckham, G. T.; Trout, B. L. Extensions to the 925 Likelihood Maximization Approach for Finding Reaction Coordi926 nates. J. Chem. Phys. 2007, 127, 034109.

927 (72) Quapp, W. Chemical Reaction Paths and Calculus of 928 Variations. Theor. Chem. Acc. 2008, 121, 227-237.

929 (73) Rosta, E.; Woodcock, H. L.; Brooks, B. R.; Hummer, G. 930 Artificial Reaction Coordinate "Tunneling" in Free-Energy Calcu931 lations: The Catalytic Reaction of RNase H. J. Comput. Chem. 2009, $93230,1634-1641$.

933 (74) Kastner, J.; Thiel, W. Bridging the Gap between Thermody934 namic Integration and Umbrella Sampling Provides a Novel Analysis 935 Method:"Umbrella Integration. J. Chem. Phys. 2005, 123, 144104.

936 (75) Kumar, A.; Balakrishna, A. M.; Nartey, W.; Manimekalai, M. S. 937 S.; Grüber, G. Redox Chemistry of Mycobacterium Tuberculosis 938 Alkylhydroperoxide Reductase E (AhpE): Structural and Mechanistic 939 Insight into a Mycoredoxin-1 Independent Reductive Pathway of 940 AhpE via Mycothiol. Free Radical Biol. Med. 2016, 97, 588-601.

941 (76) Salsbury, F. R., Jr; Knutson, S. T.; Poole, L. B.; Fetrow, J. S. 942 Functional site profiling and electrostatic analysis of cysteines 943 modifiable to cysteine sulfenic acid. Protein Sci. 2008, 17, 299-312. 944 (77) Perkins, A.; Parsonage, D.; Nelson, K. J.; Ogba, O. M.; Cheong, 945 P. H.-Y.; Poole, L. B.; Karplus, P. A. Peroxiredoxin Catalysis at Atomic 946 Resolution. Structure 2016, 24, 1668-1678.

947 (78) Zeida, A.; Gonzalez Lebrero, M. C.; Radi, R.; Trujillo, M.; 948 Estrin, D. A. Mechanism of Cysteine Oxidation by Peroxynitrite: An 949 Integrated Experimental and Theoretical Study. Arch. Biochem. 950 Biophys. 2013, 539, 81-86.

951 (79) Zeida, A.; Babbush, R.; González Lebrero, M. C.; Trujillo, M.; 952 Radi, R.; Estrin, D. A. Molecular Basis of the Mechanism of Thiol 953 Oxidation by Hydrogen Peroxide in Aqueous Solution: Challenging 954 the SN2 Paradigm. Chem. Res. Toxicol. 2012, 25, 741-746.

955 (80) Zhao, Y.; Truhlar, D. G. Density Functionals with Broad 956 Applicability in Chemistry. Acc. Chem. Res. 2008, 41, 157-167.

957 (81) Eyring, H. The Activated Complex in Chemical Reactions. J. 958 Chem. Phys. 1935, 3, 107-115.

959 (82) Pedre, B.; van Bergen, L. A. H.; Pallo, A.; Rosado, L. A.; Dufe, 960 V. T.; Molle, I. V.; Wahni, K.; Erdogan, H.; Alonso, M.; Proft, F. D.; 961 Messens, J.; et al. The Active Site Architecture in Peroxiredoxins: A 962 Case Study on Mycobacterium Tuberculosis AhpE. Chem. Commun. 963 2016, 52, 10293-10296. 